\title{
HUBUNGAN PENGETAHUAN DENGAN KECEMASAN IBU PASCA IMUNISASI DPT ANAKNYA DI KELURAHAN KOLAKAASI
}

\author{
Bangu', Yuhanah² \\ 1,2Program Studi Keperawatan Program Diploma Tiga Fakultas Sains \& Teknologi \\ Universitas Sembilanbelas Nopember Kota Kolaka
}

Email: e-mail.rektora@usnt.ac.idKolaka

\begin{abstract}
Abstrak
Imunisasi adalah pemberian suntikan kekebalan terhadap penyakit tertentu. Penyakit tersebut dapat dihindari dengan pemberian imunisasi dasar lengkap pada bayi sebelum berusia 1 tahun. Laporan dari seksi pemberantasan penyakit menular Kementrian Kesehatan di Indonesia saat ini telah terjadi penurunan penderita penyakit yang bisa dicegah dengan program imunisasi. Keberhasilan program ini atas kerja sama antara juru imunisasi dengan kader posyandu yang didukung oleh pemerintah dan kesadaran dari masyarakat. Ketidak tahuan ibu tentang imunisasi DPT merupakan penyebab utama kecemasan pada ibu setelah imunisasi DPT pada anaknya Penelitian ini bertujuan mengetahui hubungan pengetahuan dengan kecemasan ibu setelah diimunisasi DPT pada anaknya di Kelurahan Kolakaasi. Bahan dan metode yang digunakan adalah lembaran kuesioner pengetahuan dan tingkat kecemasan ibu. Jenis penelitian ini adalah survey analitik. Metode survey menggunakan cross sectional. Jumlah populasi adalah 183 ibu sebagai respondent. Hasil yang diperoleh pengetahuan ibu kateori tinggi sedangkan kecemasan kategori rendah. Analisis data dengan teknik Spearman Rho, hasil yang didapat adalah 0,658 signifikan. Terhadap 0,01. Hasil pengujian mendapat $=0,000$ berarti ada hubungan yang signifikan antara pengetahuan dengan kecemasan. Kesimpulan: Semakin tinggi pengetahuan, semakin rendah tingkat kecemasan ibu pasca mengimunisasi DPT pada anaknya di Kelurahan Kolakaasi
\end{abstract}

Keywors: Pengetahuan, imunisasi, DPT dan kecemasan 


\begin{abstract}
Immunization is an injection of immunity against certain diseases. The disease is avoided by means of a complete basic immunization in infants before 1 year of age. A report from the section on eradicating infectious diseases in the Ministry of Health in Indonesia has decreased the number of people who can be prevented by immunization programs. The success of this program is the collaboration between the immunizers and Posyandu cadres supported by the government and awareness from the community. Ignorance of mothers about DPT immunization is a major cause of anxiety in mothers after DPT immunization in their children. Materials and methods used were knowledge questionnaire sheets and maternal anxiety levels. This type of research is an analytic survey. The survey method uses cross sectional. The population was 183 mothers as respondents. The results obtained by knowledge of high category mothers while anxiety categories are low. Analysis of the data with the Spearman Rho technique, the results obtained were 0.658 significant. Towards 0.01 . Test results get $=0,000$ means there is a significant relationship between knowledge and anxiety. Conclusion: The higher the knowledge, the lower the anxiety level of mothers after immunizing the DPT to their children in the Kolakaasi Village
\end{abstract}

Keywors: Knowledge, immunization, DPT and anxiety

\title{
PENDAHULUAN
}

Imunisasi adalah suatu program pencegahan terhadap enam jenis penyakit yang sangat berbahaya pada anak. Merupakan salah satu program pemerintah yang dilaksanakan secara nasional. Hal tersebut sebagai usaha untuk mempersiapkan masa depan generasi muda yang kuat dan tangguh. Sebagai tenaga kesehatan mempunyai tugas dan tanggung jawab untuk memberikan pemahaman terhadap orang tua tentang pentingya imunisasi terhadap anak. Dengan pemberian imunisasi lengkap pada anak sesuai jadwal dapat mencegah penularan penyakit pada anak yang lain [1]

DPT adalah singkatan dari (difteri, pertusis, tetanus) Vaksin ini bergunan untuk mencegah 3 penyakit sekaligus, Cara pemberian imunisasi DPT dapat diberikan bersamaan dengan vaksin polio dan Hepatitis
B. Vaksin DPT di Indonesia diberikan melalui suntikan pada paha tengah luar dengan secara intramuscular 0, 5 cc diberikan 3 kali sejak anak umur 2 sampai 6 bulan dengan interval 1 bulan. DPT 4 diberikan pada usia anak 18 - 24 bulan. Ikatan dokter anak Indonesia [2].

Menurut data yang diperoleh 95 Kabupaten dari 20 Provinsi di Indonesia melaporkan sebanyak 622 kasus difteri, 32 diantaranya meninggal dunia. Kejadian luar biasa (KLB) difteri terjadi di beberapa Provinsi, antara lain di Sumatra Barat, Sumatra Selatan, Banten, Aceh, Sulawesi Selatan dan Kepulauan Riau. Data Kementrian Kesehatan tidak memasukan wilayah Sulawesi Tenggara sebagai wilayah dengan potensi KLB. Namun demikian, data Dinas Kesehatan Provinsi Sulawesi Tenggara melaporkan tiga kasus 
difteri dan berhasil diselamatkan oleh tim medis [1].

Berdasarkan uraian latar belakang tersebut, maka permasalahan yang akan dikaji diarahkan untuk mengetahui hubungan pengetahuan dengan kecemasan ibu pasca imunisasi DPT di Kelurahan Kolakaasi Kabupaten Kolaka.

Kelurahan Kolakaasi berada di wilayah Kecamatan Latambaga Kabupaten Kolaka Provinsi Sulawesi Tenggara. Sasaran terbanyak pada tahun 2018 sebanyak 183 bayi. Sedangkan cakupan imunisasi DPT 3 sampai bulan Agustus 2019 adalah 66 bayi (33, $6 \%)$.

Hasil wawancara tanggal 5 Agustus 2019 terhadap 20 ibu di Posyandu Cakalang Kelurahan Kolakaasi, 15 responden menjawab tidak jelas tujuan pemberian imunisasi DPT pada bayi. Dan 5 reponden mengatakan cemas karena bayi mereka demam, kemerahan didaerah suntikan serta menengis seharian setelah diimunisasi DPT. Bahkan mereka mengatakan tidak akan tidak akan ke Posyandu lagi, sekalipun ada anjuran dari Kelurahan dan Puskesmas. Menurut mereka yang merasakan dampaknya setelah anak diimunisasi khususnya DPT bukan petugas kelurahan atau petugas Puskesmas tetapi ibu dan keluarga bayi tersebut.

Untuk mengatasi hal tersebut diatas pemberian Informasi sangatlah diperlukan berupa pemasangan spandu, baliho dan poster tentang dampak anak yang tidak diimunisasi di tempat - tempat strategis seperi: di kantor Kelurahan, Puskesmas, pusat perbelajaan dan di Posyandu.. Sumber informasi juga dapat diperoleh melalui penyuluhan oleh petugas kesehatan khususnya jurim, maupun kader kesehatan.

Penelitian ini bertjuan untuk mengetahui hubungan pengetahuan dengan kecemasan tentang imunisasi DPT pada anak di Kelurahan Kolakaasi. Memberikan pemahaman dan kesadaran ibu akan pentingnya pemberian imunisasi sehingga mereka mau mengujungi Posyandu dan memberikan imunisasi DPT pada anaknya.

\section{METODOLOGI}

Metode penelitian survey analitik rancangan survey cross sectional, yaitu suatu penelitian mempelajari korelasi antara faktor faktor resiko dengan efek. Dengan cara pengumpulan data sekaligus, observasi dan pengukuran dilakukan dalam waktu bersamaan [3]. Penelitian dilaksanakan pada tanggal 5 Agustus sampai 30 September 2019, di Kelurahan Kolakaasi Kecamatan Latambaga Kabupaten Kolaka Propinsi Sulawesi Tenggara.

Populasi adalah keseluruhan objek yang akan diteliti, dalam penelitian ini adalah keseluruhan ibu yang mempunyai bayi yang berada di Kelurahan Kolakaasi sebanyak 183 orang. Sampel berjumlah 60 responden yang mewakili sebahagian dari populasi yang akan diteliti. Pengambilan sampel dengan cara 
simple random sampling yaitu pengambilan sampel dari sebahagian anggota populasi secara acak yang memenuh criteria inklusi : Bersedia menjadi responden, mampu berkomunikasi dan berdomisili di Kelurahan Kolakaasi. Sedangkan kriteria eksklusi sebagai berikut: Tidak bersedia menjadi responden, tidak mampu berkomunikasi dan tidak berdomisili di Kelurahan Kolakaasi.

Cara pengumpulan data dengan cara membagi lembar kuesioner kepada responden yang akan dijadikan sampel kemudian dikumpulkan kembali lalu di tabulasi dan dianalisa. Sebahagian data juga diperoleh dari juru imunisasi (jurim) Puskemas Kolakaasi dan catatan dari posyandu.

Proses analisis pengolahan data adalah: tabulasi data, memberikan coding, Scoring editing, dan transferring. Data tersebut dianalisis dengan cara Correlation product moment [4].

Data yang yang sudah terkumpul lalu diolah dengan menggunakan komputerisasi SPSS, pengetahuan dan kecemasan responden di tentukan berdasarkan rentang nilai :
a. $80-100 \%$ : Kategori Tinggi.
b. $60-<80 \% \quad$ : Kategori sedang
c. $<56 \%$ : Kategori rendah [5]

Instrumen penelitian ini adalah lembaran kuesioner yang berisi kecemasan ibu pasca imunisasi DPT dan kuesioner pengetahuan tentang imunisasi DPT di Kelurahan Kolakaasi

\section{HASIL DAN PEMBAHASAN}

Penelitian ini dilaksanakan di Kelurahan Kolakaasi Kecamatan Latambaga Kabupaten Kolaka pada tanggal 5 Agustus sampai tanggal 30 September 2019, menggunakan teknik random sampling berjumlah 60 orang, disajikan dalam bentuk tebel distribusi dan dianalisis. Pengujian dibantu dengan komputer paket statistik SPSS (Statistik produc and service salutation) dengan menggunakan uji statistic Spearman Rho dan dijelaskan dalam bentuk tabel disertai penjelasan tabel sesuai narasi.

Tabel. 1 Distribusi responden berdasarkan usia di Kelurahan Kolakaasi tahun 2019

\begin{tabular}{ccc}
\hline Usia & Jumlah & $(\%)$ \\
\hline$\leq 20$ Tahun & 3 & 5 \\
$21-25$ Tahun & 19 & 31,67 \\
$26-$ 30 Tahun & 14 & 23,33 \\
$\geq 31$ Tahun & 24 & 40 \\
\hline & 60 & 100 \\
\hline
\end{tabular}

Berdasarkan tabel1 di atas menunjukan dari 60 repsonden yang diteliti kelompok umur terbanyak adalah berusia $\geq 31$ tahun berjumlah 24 orang (40\%) dan paling sedikit usia $\leq 20$ tahun berjumlah 3 orang (5 $\%)$, 
Table 2. Distribusi Frekuensi responden berdasarskan jumlah anak di Kelurahan Kolakaasi tahun 1019

\begin{tabular}{|c|c|c|}
\hline Jumlah anak & Jumlah & (\%) \\
\hline $1-2$ Orang & 41 & 68,34 \\
\hline $3-5$ Orang & 16 & 26,66 \\
\hline$>5$ Orang & 3 & 5 \\
\hline
\end{tabular}

Dari tabe; di atas dapat disimpulkan bahwa dari 60 responden terdapat 41 orang $(68,34 \%)$ dengan jumlah anak $1-2$ orang, 16 responden $(26,66 \%)$ dengan jumlah anak $3-5$ orang dan 3 orang $(5 \%)$ dengan jumlah anak $>5$ jumlah anak.

Table 3. Distribusi responden berdasarkan pendidikan di Kelurahan Kolakaasi tahun 2019

\begin{tabular}{lll}
\hline $\begin{array}{l}\text { Tingkat } \\
\text { Pendidikan }\end{array}$ & Jumlah & (\%) \\
\hline SD & 24 & 40 \\
SMP & 16 & 26,7 \\
SMA & 12 & 20 \\
S1 & 7 & 11.7 \\
S2 & 1 & 1.7 \\
& 60 & 100 \\
\hline
\end{tabular}

Berdasarkan tebel 3 diatas pendidikan ibu menunjukkan paling sedikit adalah tingkat pendidikan S2 sebanyak 1 orang (1,7\%). Kelompok pendidikan paling banyak adalah SD jumlah 24 responden (40\%).
Tabel 4. Distribusi responden berdasarkan pengetahuan di Kelurahan Kolakaasi tahun 2019

\begin{tabular}{lcc}
\hline $\begin{array}{c}\text { Kategori } \\
\text { Pengetahuan }\end{array}$ & Frekuensi & Persentase (\%) \\
\hline Rendah & 22 & 36,66 \\
Sedang & 12 & 20 \\
Tinggi & 26 & 43,34 \\
& 60 & 100 \\
\hline
\end{tabular}

Pada tabel 4 di atas dapat menunjukan bahwa dari 60 responden, yang mempunyai pengetahuan tinggi berjumlah 26 responden (43,34\%). Sedangkan yang mempunyai pengetahuan rendah adalah 22 responden $(36,66 \%)$.

Tabel 5.Distribusi responden berdasarkan kecemasan tingkat ibu di Kelurahan Kolakaasi tahun 2019

\begin{tabular}{lcc}
\hline \multicolumn{1}{c}{ Kecemasan } & Frekuensi & Persentase (\%) \\
\hline Rendah & 29 & 48,33 \\
Sedang & 11 & 18,33 \\
Tinggi & 20 & 33,34 \\
Jumlah: & & 100 \\
& & \\
\hline
\end{tabular}

Berdasarkan tabel di atas dapat disimlpulkan bahwa terdapat 29 responden $(48,33 \%)$ dengan tingkat kecemasan rendah, 11 responden $(18,33 \%)$ dengan tingkat kecemasan sedang dan 20 responden $(33,34 \%)$ dengan tingkat kecemasan tinggi. 
Tabel 6. Korelasi pengetahuan dengan kecemasan ibu di Kelurahan Kolakaasi tahun 2019

\begin{tabular}{lllll}
\hline & & Pengatahuan & Kecemasan \\
\hline $\begin{array}{l}\text { Spearman' } \\
\text { s rho }\end{array}$ & Pengatahuan & Correlation & 1.000 & .586 \\
& & coefficient & & \\
& Sig. 2 &. & .000 \\
& $\mathrm{~N}$ & 60 & 60 \\
& Kecemasan & Correlation & .586 & 1.000 \\
& & coefficient & & \\
& Sig. 2 & .000 &. \\
& $\mathrm{~N}$ & 60 & 60 \\
\hline
\end{tabular}

Sumber : Data Primer tahun 2019

Berdasarkan tabel 6 menunjukan dari 60 orang nilai signifikan adalah 0.000 maka dapat disimpulkan bahwa ada hubungan yang bermakna antara pengetahuan dengan kecemasan ibu setelah imunisasi DPT pada balita di Kelurahan Kolakaasi.

Table di atas juga terdapat korelasi antara pengatahuan dengan tingkat kecemasan adalah 0.586. Artinya terdapat hubungan sedang tingkat kecemasan dengan pengetahuan ibu pasca imunisasi DPT ulang pada balita di kelurahan kolakaasi.

Pengetahuan adalah suatu kekuatan berupa yang didapat dari pengetahuan setelah orang tersebut melakukan penginderaan jauh dari objek tertentu. Atau hasil tahu dari manusia [3].

Pendidikan adalah suatu usaha atau kegiatan untuk membantu individu dalam meningkatkan kemampuan/perilaku, agar terjadi perubahan sikap dan tingkah laku individu dalam memelihara perilaku hidup sehat serta berperan aktif dalam upaya mewujudkan derajat kesehatan yang optimal [6].

Dari 60 ibu sampel yang akan diteliti, terbanyak berpengetahuan tinggi berjumlah 26 responden dan yang berpengetahuan rendah berjumlah 12 responden. Dari uraian tersebut menunjukan bahwa tingkat pengtahuan ibu tentang imunisasi DPT di Kelurahan Kolakaasi umumya baik. Faktor - faktor yang mempengaruhi adalah pendidikan, informasi, sikap dan praktek ibu dalam pemberian imunisasi DPT pada anak. Sesuai hasil penelitian Refrensi [7] bahwa informasi, tempat tinggal, jenis pekerjaan, pendidikan dan sikap ibu adalah faktor yang mempengaruhi terhadap pemberian imunisasi.

Tingkat pendidikan sangat berpengaruh terhadap pengetahuan. Berdasarkan hasil penelitian di Kelurahan Kolakaasi paling banyak berpendidikan SMP sampai sarjana berjumlah 36 orang termasuk kategori pengetahuan baik. Sedangkan pendidikan SD berjumlah 26 orang termasuk kategori pengetahuan rendah. Dengan demikian ibu yang berpendidikan tinggi sesuai dengan kenyataan dilapangan baik pengetahuannya dibandingkan dengan ibu yang berpendidikan SD. Hal tersebut berdampak pada cakupan imunisasi DPT 3 di Kelurahan Kolakaasi. Dari bulan Januari sampai Agustus cakupan DPT 3 adalah 66 bayi dari sasaran 183 bayi tahun 2019. Berarti ibu yang berpendidikan tinggi lebih muda memahami informasi yang diterimanya. 
Informasih yang diperoleh ibu secara langsung seperti penyuluhan yang dilakukan kader di posyandu maupun tidak langsung seperti iklan dan poster. Hal tersebut sesuai penelitian Refrensi [8]. Bahwa semakin tinggi pendidikan semakin meningkat kemampuan melaksanakan peran dan fungsi yang lebih baik khususnya dalam melaksanakan kegiatan imunisasi.

Perubahan perilaku bisa terjadi sikap mental yang sangat kuat, serta adanya penambahan pengetahuan dan keterampilan. Peningkatan kepercayaan diri didertai peningkatan pengetahuan kearah yang lebih baik disertai adanya perubahan perilaku dari tidak mau menjadi mau mengikuti kegiatan yang ada dalam masyarakat. Salah satunya adalah kegiatan imunisasi DPT di Posyandu [6].

Kecemasan adalah kekhawatiran atau ketidak nyamanan seseorang terhadap suatu objek. Hal ini merupakan peringatan atau isyarat kewaspadaan pada individu akan adanya ancaman atau bahaya sehingga individu bisa bertindak untuk menghadapi ancaman tersebut [9]. Berdasarkan survey penelitih menemukan 6 responden yang berpengetahuan rendah dan tingkat kecemasan rendah, mereka mengatakan pengalaman yang lalu saat diimunisasi bayinya di posyandu mengalami demam tinggi selama 2 - 3 hari, berdasarkan hal tersebut mereka tidak melakukan /imunisasi ulang karena perasaan takut dan ancaman akan bahaya pada bayi mereka.

Berdasarkan hasil penelitian diperoleh responden dengan kecemasan rendah berjumlah 29 responden, dikarenakan keaktifan juru imunisasi dari Puskesmas Kolakaasi bersama kader kesehatan dalam memberikan penyuluhan secara rutin di posyandu Selain aktif mengikuti kegiatan penyuluhan, keterlibatan ibu - ibu PKK tingkat Kabupaten sampai Kelurahan serta adanya program dari pemerintah Kabupaten Kolaka yang mewajibkan tiap Puskesmas dan kelurahan untuk meningkatkan pelayanan kesehatan khususnya pelayanan program posyandu yang salah satunya program tersebut adalah pelayanan imunisasi dasar pada bayi.

Korelasi antara pengetahuan dengan kecemasan ibu pasca imunisasi DPT adalah 0,586 signifikan terhadap $=0,01$ hasil pengujian didapatkan $p$ value $=0,000$. nilai hitung lebih besar dari $t$ tabel, artinya ada hubungan yang signifikan antara pengetahuan dengan kecemasan pasca imunisasi DPT ulang di Kelurahan Kolakaasi.

Menurut Refrensi [10] Tingkat pengetahuan ibu mempengaruhi informasi yang diterima. Berbagai sumber informasi tentang imunisasi khususnya imunisasi DPT berupa pemasangan spandu, baliho dan poster tentang dampak anak yang tidak diimunisasi. Sumber Informasi lain dapat diperoleh dari juru imunisasi dan kader 
kesehatan melalui penyuluhan di pos pelayanan terpadu (Posyandu) tentang pentingnya imunisasi khususnya imunisasi DPT. Dengan demikian semakin tinggi pengetahuan seseorang semakin muda menerima informasi.

Selain faktor pendidikan dan informasi pengalaman ibu juga mempengaruhi pengetahuan terhadap imunisasi. Contoh ibu sudah mempunyai pengalaman memberikan imunisasi pada anak sebelumnya, maka ibu tersebut akan memberikan imunisasi DPT anak berikutnya, tetapi ibu yang tidak memiliki pengalaman setelah anaknya diimunisasi dan mendapat reaksi seperti demam, rewel dan sakit ditempat suntukan maka ibu tersebut tidak akan memberikan imunisasi pada anak berikutnya. Di Kelurahan Kolakaasi kebanyakan ibu mempunai seorang anak sebanyak 41 orang dari 60 responden. Hal inilah salah satu penyebab rendahnya cakupan imunisasi DPT di Kelurahan Kolakaasi. Karena peristiwa yang telah terjadi dimasa lampau yang dialami ibu akan dijadikan sebagai pembelajaran yang berharga, dengan kata lain pengalaman adalah guru yang sangat berharga [3].

Penelitian lain yang dilakukan oleh Refrensi [11] Jenis dan kandungan zat kimia dari vaksin berdampak pasca imunisasi pada bayi, hal ini sangat berpengaruh pada ibu untuk tidak memberikan vaksin pada anaknya. Sehingga berkembang anggapan yang salah dimasyarakat tentang imunisasi, para orang tua merasa khawatir akan bahaya setelah anak mereka divaksinasi. Sesuai dengan haisl penelitian yang telah dilakukan, komposisi vaksin menyebabkan $32 \%$ bayi mengalami alergi, berarti ada pengaruh antara minat ibu dengan komposisi vaksin.

Petugas kesehatan dapat berperan dan bertanggung jawab dalam memberikan pemahaman tentang imunisasi agar ibu percaya dan akhirnya dapat menurunkan kecemasan. Kepercayaan mempengaruhi pengetahuan yang akan memberiakan motivasi, informasi dan dapat meruba persepsi manusia secara nyata agar dapat menentukan sikap dalam mengambil keputusan [6].

Dari uraian tersebut diatas dapat disimpulkan bahwa pasca imunisasi DPT, semakin tinggi pengetahuan, semakin rendah tingkat kecemasan. Semakin tinggi tingkat pendidikan semakin tinggi pengetahuan tentang imunisasi khususnya imunisasi DPT. Menurut Refrensi [3] domain penting untuk membentuk tindakan seseorang adalah koginitif atau pengetahuan.

Menurut Refrensi [12], bayi yang dimunisasi lengkap perkembangan kognitifnya baik sedangkan yang tidak diimunisasi lengkap perkembangan kognitifnya kurang. 


\section{KESIMPULAN}

Dari pembahasan diatas dapat disimpulkan: Pertama, pengetahuan ibu 26 orang dari 60 reponden kateori tinggi. Kedua, kecemasan ibu 29 orang dari 60 responden kategori rendah. Ketiga, ada hubungan yang signifikan antara pengetahuan dengan kecemasan. Yang menjadi temuan adalah: Semakin tinggi pengetahuan seseorang semakin banyak informasi yang diperoleh. Semakin rendah tingkat kecemasan semakin tinggi tingkat pengetahuan ibu. Tempat tinggal, jenis pekerjaan, pendidikan sikap dan praktek sangat berpengaruh terhadap kelengkapan imunisasi pada anak

Saran kepada juru imunisasi dan kader kesehatan agar lebih ditingkatkan kenerjanya dalam memberikan pelayanan di Posyandu sesuai dadual tiap bulan. Kepada petugas kesehatan khususnya di wilayah kerja Puskesmas Kolakaasi lebih giat lagi memberikan penyuluhan tentang pentingnya imunisas DPT: pengertian, manfaat dan efek samping, agar cakupan imunisasi khususnya DPT dapat tercapai sesuai dengan target. Untuk penelitih berikutnya diharapkan untuk meneliti jenis imunisasi yang lain seperi: BCG, polio dan campak.

\section{UCAPAN TERIMA KASIH}

Proses penelitian ini telah melewati perjalanan panjang dan peneliti sepenuhnya menyadari begitu banyak kesulitan serta hambatan yang ditemukan, namun peneliti tetap berusaha semaksimal mungkin menyelesaikan penelitian ini. Sekaitan dengan itu perlu menyampaikan ucapan terima kasih dan penghargaan yang tak terhingga kepada:

1. Bapak Kepala Dinas Kesehatan Kabupaten Kolaka selaku penanggung jawab bidang Kesehatan di Kabupaten Kolaka.

2. Ibu Kepala Puskesmas Kolakaasi beserta staf

3. Bapak Ns.Abdul Salam S.Kep yang telah memberi masukan, koreksi dan saran.

\section{DAFTAR PUSTAKA}

1. Kemenkes RI, 2018. Pemerintah Optimis KLB Difteri Bisa Teratasi: Jakrta 2018

2. Ikatan Dokter Anak Indonesia (IDAI). JADWAL IMUNISASI 2017. Jakarta: 2017.

3. Notoatmodjo S. 2010. Metodologi Penelitian Kesehatan. Edisi revisi Jakarta: PT Rineka Cipta

4. Sugiyono. 2011. Metode Penelitian Kuantitatif Kualitatif Dan $R \& D$. Bandung: Alfabeta

5. Ircham Machfoedz. 2013. Metode Penelitian Kuantitatif \& Kualitatif: Fitramaya Yogyakarta: 2013 hlm. 147 159

6. Nursalam dan Efendi F, 2009 Pendidikan Dalam Keperawatan Jakarta: Salemba Medika

7. Bofarraj, Mabrouka AM. "Knowledge, attitude and practices of mothers regarding immunization of infants and preschool 
children at Al-Beida City, Libya 2008." Egyptian Journal of Pediatric Allergy and Immunology (The) 9.1 (2011).

8. Dewi, Atika Putri, Eryati Darwin, and Edison Edison. "Hubungan Tingkat Pengetahuan lbu dengan Pemberian Imunisasi Dasar Lengkap pada Bayi di Kelurahan Parupuk Tabing Wilayah Kerja Puskesmas Lubuk Buaya Kota Padang Tahun 2013." Jurnal Kesehatan Andalas 3.2 (2014).

9. North American Nursing Diagnosis Association (NANDA) - I. Diagnosis Keperawatan Definisi Dan Klasifika 2018 2020. ED 11- Jakarta: EGC. 2018: 315 127

10. Widayati, Siti Nur. "Hubungan Tingkat Pengetahuan Ibu Tentang Imunisasi Polio Dengan Status Kelengkapan Imunisasi Polio Di Wilayah Kerja Puskesmas Tanon I Sragen." Gaster: Jurnal Kesehatan 9.2 (2012): 33-45.

11. Chandra, D. 2017. Hubungan Tingkat Pengetahuan, Pekerjaan, Kepercayaan Dan Dukungan keluarga Dengan Pemberian Imunisasi Dasar Pada Batita Di Posyandu Di Wilayah Kerja, 3(2), 47-56.

12. Kaunang, Melisa C., Sefti Rompas, and Yolanda Bataha. "Hubungan Pemberian Imunisasi Dasar Dengan Tumbuh Kembang Pada Bayi (0-1 Tahun) Di Puskesmas Kembes Kecamatan Tombulu Kabupaten Minahasa." JURNAL KEPERAWATAN 4.1 (2016). 